\title{
CARCINOGENICITY OF CHROMIUM AMONG STEEL WORKERS: A COMPARATIVE CROSS SECTIONAL STUDY
}

\author{
By \\ Hassanein H.M.; Abbas R.A.*; El-Hawary A.*, \\ Hammad S.A. **, and Saad A.***
}

FROM

Departments of Forensic Medicine and Clinical Toxicology, Community, Environmental and Occupational Medicine*; Faculty of Medicine - Zagazig University; Human Cytogentics **, and Environmental and Occupational Medicine ***, National Research Centre, Egypt

\begin{abstract}
Background: Certain chromium compounds are prominent metal carcinogens in both occupational and environmental settings. Objectives: The present study aimed to determine cytogenetic changes in the form of sister chromatid exchanges (SCEs) and predict chromium carcinogenicity in steel foundry workers; moreover, study the relationships between SCEs and tumor marker (CA 15-3) with the urinary chromium levels in the same group. Subjects and methods: The study included three groups; 20 apparently healthy male steel foundry workers, from different work sections, 20 apparently healthy male workers not exposed to chromium compounds, as a negative control group, and 10 lung cancer male patients from the National Cancer Institute, as a positive control group. All participants were interviewed using a pre-constructed questionnaire. Furthermore, they were subjected to urinary chromium level estimation, cytogentic study in the form of SCEs, and tumor marker (CA15-3) level measurement. Results: Steel workers had significantly higher levels of urinary chromium $(5.5 \pm 1.010 \mathrm{~g} / \mathrm{L})$ compared to the other two groups $(0.7 \pm 0.19$ and $0.8 \pm 0.220 \mathrm{~g} / \mathrm{L})$ $(\mathrm{P}<0.001)$. Also, steel workers had significantly higher SCEs and CA15-3 levels compared to the negative controls (non-exposed workers) $(\mathrm{P}<0.001)$, but significantly
\end{abstract}


lower than those of the positive controls (lung cancer patients) $(\mathrm{P}<0.01)$. Moreover in the studied steel workers, there were significant positive correlations between urinary chromium levels and both SCEs and CA15-3 levels. Conclusion: It could be concluded that, unprotected occupational exposure to chromium in steel production industry can carry the risk of developing cytogenetic changes and cancer. These effects can be predicted by estimation of SCEs and tumor marker (CA 15-3) levels. Recommendations: Periodic medical examinations and biological monitoring of steel foundry workers, along with improving working conditions are recommended.

Key words: Steel foundry workers, urinary chromium, sister chromatid exchanges, and tumor marker (CA15-3).

\section{Introduction}

Early in the $20^{\text {th }}$ century, chromium became widely used in steel production. Today, the main uses of chromium are in alloys and in the production of various chemical forms of chromium used in pigments, textiles, metal surface treatments and corrosion control, and tanning. Chromium and its compounds protect against rust, provide color, conserve energy as components of catalysts, prevent decay, and resist soiling. In fact, the uses of chromium are so extensive that today's world would be almost unrecognizable without it (Sawyer, 1994).

Chromium is a very complex and versatile metal whose harmful effects are heavily dependent on valence. In addition to metallic chromium (valence 0 ), other valences found in industry are the $+2,+3$, $+4,+5$, and +6 combining states. Divalent chromium $\left(\mathrm{Cr}^{+2}\right)$ is of minor importance in industrial exposures because it readily oxidizes to the trivalent state $\left(\mathrm{Cr}^{+3}\right)$. Therefore, its harmful effects are mostly those of $\mathrm{Cr}^{+3}$. The tetravalent and pentavalent $\left(\mathrm{Cr}^{+4}\right.$ and $\left.\mathrm{Cr}^{+5}\right)$ forms are unstable intermediates in chemical production. They pose no significant human health risks. Trivalent $\left(\mathrm{Cr}^{+3}\right)$ and hexavalent $\left(\mathrm{Cr}^{+6}\right)$ chromium are the most common valence types in the workplace and the only compounds known to be significantly associated with human disease. However, from an exposure viewpoint, $\mathrm{Cr}^{+6}$ is potentially more hazardous than $\mathrm{Cr}^{+3}$ (Stearns and Wetterhahn, 1994).

Hexavalent chromium compounds have been declared as potent occupational carcinogens by the International Agency for Research on Cancer (IARC) through epidemiological studies among workers in chrome plating, stainless steel, and pigment industries. Further studies have provided further epidemiological, experimen- 
tal, and mechanistic data, which support the IARC conclusions. Moreover, many studies found that, metallic chromium (valence 0$), \mathrm{Cr}^{+3}$, and $\mathrm{Cr}^{+6}$ can induce a variety of genetic and related effects in vitro (Zhitjovich et al., 2002).

Till now, there is no good evidence that inhaled $\mathrm{Cr}^{+3}$, at currently allowable concentrations, poses any occupational or environmental health risk. However, exposure to $\mathrm{Cr}^{+6}$ dichromates has been known for more than a century to be associated with induction of cancer in humans (Trzeciak et al., 2000). The ability of hexavalent compounds to produce cancer is a function of their solubility in tissue fluids. Inhaled chromium compounds that dissolve slowly in tissue fluids appear to pose the greatest risk of lung cancer. Carcinogenicity requires sufficient exposures, as is only encountered in well-defined occupational settings, and is site specific, being specifically targeted to the lung, and, in some cases, to the sinonasal cavity. Increased death rates for cancers at other sites, which were occasionally reported in some epidemiological studies, were almost not statistically significant and inconsistent $(\mathrm{Hu}-$ vinen et al., 1996).

A high incidence rate of lung cancer, among adult male workers at this steel foundry (7.5\% in the year 2005), was detected from the Occupational Health Clinic records, Health Insurance Hospital, 10th of Ramadan City. So, the present study aimed to determine cytogentic changes in the form of sister chromatid exchanges (SCEs) and predict chromium carcinogenicity in steel foundry workers, in addition, study the relationships between SCEs and tumor marker (CA 15-3) with the urinary chromium levels in the same group.

\section{Subjects and Methods}

\section{Study design and setting:}

This comparative cross-sectional study was conducted at the clinics of ASEC Company (a chromium-alloyed steel foundry) at $10^{\text {th }}$ of Ramadan City, the Sweet Source Company at 10th of Ramadan City, Sharkia Governorate, and at the National Cancer Institute in Cairo.

\section{Industrial process:}

The industrial process in this chromium-alloyed steel foundry is composed of the following steps:

1-Melting and alloying of metal: where scrap iron or steel are mixed with ferrochrome alloy. The mix is then charged into the top of electric induction furnaces; where heating up to a temperature of $1400{ }^{\circ} \mathrm{C}$ is required. 
2-Moulding and core-making: the molten steel alloy is then poured manually using ladles into molds, which are formed of sand and other binders to increase the strength of sand. Then, the poured alloy is left for up to 18 hours and allowed to cool in order to acquire a consistently shaped product. Finally, the cast-steel is recovered from sand using vibrating machines.

3-Heat treatment: the chromium-alloyed steel balls are then reheated in heat treatment furnaces up to $800{ }^{\circ} \mathrm{C}$. In order to have a certain degree of hardness, the hot red balls are poured into warm water or oil $\left(40{ }^{\circ} \mathrm{C}\right)$.

4-Tempering: then the chromium-alloyed steel balls are reheated in electric furnaces up to $400{ }^{\circ} \mathrm{C}$ for 4 hours.

5-Finishing: which involves grinding and welding of pieces in order to obtain smooth and shinny final product.

NB (1): During the previously mentioned steps of the industrial process, huge quantities of iron and chromium fumes and particles were evolved.

NB (2): Inadequate ventilation and lack of personal protection were very unsuitable in such hot, noisy, and heavily polluted work environment.

\section{A) Subjects}

\section{A-1) Steel foundry workers:}

Twenty apparently healthy male workers out of 31 workers form the morning shift; from different work sections at the steel foundry, were included in this study according to the following criteria:

a) Regular and direct exposure to chromium aerosols.

b) Non-smokers.

c) No previous (before joining the job) occupational exposure to known mutagens (Baxter, 2007).

\section{A-2) Non-exposed workers (Negative}

\section{controls):}

Twenty apparently healthy male subjects, employed at the Sweet Source Company, were selected according to the following criteria:

a) Comparable to the studied steel foundry workers as regards age, sex, socioeconomic standard, and duration of employment.

b) Non-smokers.

c) Not occupationally exposed to known mutagens.

A-3) Lung cancer patients (Positive controls):

Ten male patients with lung cancer, 
from the National Cancer Institute, were also included in this study.

\section{B) Methods}

\section{B-1) Questionnaire:}

After obtaining informed consents from all participants, they were asked to fill a pre-constructed questionnaire, which included personal data, and a detailed occupational history.

\section{B-2) Estimation of chromium in urine:}

Chromium was determined in the urine of all participants. Urine samples were collected in sterile containers during work shift to be analyzed using the Atomic Absorption Spectrophotometer (Buck Scientific Model 210 VGP) at the Central Laboratory of the Faculty of Veterinary Medicine, Zagazig University; where readings were obtained at a wavelength 357.9 nm (Schaller, 1996).

\section{B-3) Cytogenetic analysis:}

All participants in the study were subjected to cytogenetic analysis, for detecting sister chromatid exchange frequencies formation using culture methods (Verma and Babu, 1989), as follows;

-Harvesting form the buffy coat and leucocytes obtained from the collected heparinized blood samples (5 $\mathrm{ml}$ blood).
-Staining of the prepared slides with $50 \mathrm{mg} / \mathrm{ml}$ of Hoechst 33258 dye in distilled water. Then, slides were rinsed and put in warm tray at $70{ }^{\circ} \mathrm{C}$ and allowed to dry.

-Counting and scoring of sister chromatid exchanges (SCEs) were done only in cells which had 46 chromosomes. Usually 20-30 complete cells were analyzed from each case and SCEs were scored per metaphases. SCEs can be detected as areas of reciprocal staining intensities in chromosomes in metaphase cells that have been replicated.

\section{B-4) Estimation of tumor marker}

\section{(CA15-3):}

Tumor marker (Cancer Antigen 15-3) (CA15-3) was measured in the collected serum samples from all participants by enzyme immunoassay; where specific monoclonal anti-cancer antigen15-3 antibodies were coated on to microtitration wells. Then, diluted test sera were applied and incubated. If human cancer antigen15-3 was present in serum samples, it would combine with the antibody in the wells. On addition of the substrate, color developed only in the wells in which cancer antigen was present. The concentration of cancer antigen15-3 is directly proportional to the color intensity of the test samples. 


\section{B-5) Statistical analysis:}

The collected data was statistically analyzed using SPSS software, version 13.0 (Neter et al., 1993). Comparison between group means was done using Analysis of Variance (ANOVA) and Post hoc least significant differences (LSD). Pearson correlation coefficient ( $r$ ) was used for testing the association between two continuous variables. The significance level was considered at $\mathrm{P}$-value $<0.05$.

\section{Results}

In the present study, the means of ages of the studied steel workers, negative controls, and positive controls were (39.2 \pm $3.6 \mathrm{y}, 36.3 \pm 2.3 \mathrm{y}$, and $61.4 \pm 1.1 \mathrm{y}$, respectively). Table (1) demonstrates some occupational data of the studied steel workers; where, furnaces and molding workers represented the majority (70\%), while finishing workers represented only (30\%). Moreover, the mean duration of employment was $(11.6 \pm 0.6 \mathrm{y})$, the mean of their working hours per day was $(8.0 \pm$ $0.1 \mathrm{~h} / \mathrm{d}$ ), and the mean of their vacation days / week was $(1.0 \pm 0.0)$. Finally, it was found that, none of the studied steel foun- dry workers used personal protective equipment regularly during work.

In table (2), the results demonstrate that steel workers had significantly higher mean level of urinary chromium compared to the other two groups $(\mathrm{P}<0.001)$. Moreover, there were very high statistical significant differences among the three studied groups regarding the tumor marker (CA15-3) level and SCEs frequency $(\mathrm{P}<0.001)$. The tumor marker CA15-3 levels and SCEs frequency in the steel workers were significantly higher compared to the negative controls $(\mathrm{P}<0.001)$; while they were significantly lower compared to the positive controls $(\mathrm{P}<0.01)$.

Table (3) shows that in the studied steel workers, there were significant positive correlations between urinary chromium levels and both SCEs frequency and tumor marker (CA15-3) levels.

Figures (1,2 and 3, respectively) demonstrate, the frequencies of SCEs in a nonexposed worker (a negative control), in an exposed worker (a steel worker), and in a lung cancer case (a positive control). 
Table (1): Some occupational data of the studied steel workers.

\begin{tabular}{|lr|r|}
\hline \multicolumn{2}{|l|}{ Some Occupational data of steel workers } & \\
\hline Work section & & \\
Furnace \& Molding workers & $\mathrm{N}(\%)$ & $14(70.0 \%)$ \\
Finishing workers & $\mathrm{N}(\%)$ & $6(30.0 \%)$ \\
\hline Working duration (years) & $(\overline{\mathrm{X}} \pm \mathrm{SD})$ & $11.6 \pm 0.6$ \\
\hline Hours of work / day & $(\overline{\mathrm{X}} \pm \mathrm{SD})$ & $8.0 \pm 0.1$ \\
\hline Vacation days / week & $(\overline{\mathrm{X}} \pm \mathrm{SD})$ & $1.0 \pm 0.0$ \\
\hline Regular use of personal protective measures & $\mathrm{N}(\%)$ & $0(0.0 \%)$ \\
\hline
\end{tabular}

Table (2): Comparison of the urinary chromium levels, tumor marker (CA15-3) levels, and sister chromatid exchange frequency (SCE) among the three studied groups.

\begin{tabular}{|c|c|c|c|c|c|c|c|}
\hline & \multicolumn{2}{|c|}{$\begin{array}{c}\text { Negative Controls } \\
(\mathrm{N}=20)\end{array}$} & \multicolumn{2}{|c|}{$\begin{array}{l}\text { Steel workers } \\
\qquad(\mathrm{N}=20)\end{array}$} & \multicolumn{2}{|c|}{$\begin{array}{l}\text { Positive controls } \\
\qquad(\mathrm{N}=10)\end{array}$} & \multirow{2}{*}{\begin{tabular}{|l|} 
ANOVA \\
P-value \\
\end{tabular}} \\
\hline & $X$ & $\mathrm{SD}$ & $X$ & $\mathrm{SD}$ & $X$ & $\mathrm{SD}$ & \\
\hline \multirow{2}{*}{$\begin{array}{c}\text { Urinary } \mathrm{Cr}(\mu \mathrm{g} / \mathrm{L}) \\
(\mathrm{LSD})\end{array}$} & 0.7 & \multirow[t]{2}{*}{0.19} & 5.5 & \multirow[t]{2}{*}{1.01} & 0.8 & \multirow[t]{2}{*}{0.22} & \multirow[t]{2}{*}{$<0.001$} \\
\hline & (a) & & $(a, b)$ & & (b) & & \\
\hline \multirow{2}{*}{$\begin{array}{l}\text { CA15-3 (U /ml) } \\
\text { (LSD) }\end{array}$} & 4.2 & \multirow[t]{2}{*}{1.1} & 28.8 & \multirow[t]{2}{*}{5.03} & 34.6 & \multirow[t]{2}{*}{3.4} & \multirow[t]{2}{*}{$<0.001$} \\
\hline & $(\mathrm{a}, \mathrm{c})$ & & $(a, b)$ & & $(b, c)$ & & \\
\hline \multirow{2}{*}{$\begin{array}{l}\text { SCE / cell } \\
\text { (LSD) }\end{array}$} & 3.6 & \multirow[t]{2}{*}{0.56} & 6.7 & \multirow[t]{2}{*}{0.26} & 13.4 & \multirow[t]{2}{*}{1.24} & \multirow[t]{2}{*}{$<0.001$} \\
\hline & $(\mathrm{a}, \mathrm{c})$ & & $(a, b)$ & & $(b, c)$ & & \\
\hline
\end{tabular}

N.B. a: significant difference between steel workers and negative controls, $b$ : significant difference between steel workers and positive controls, c: significant difference between positive controls and negative controls. 
Table (3): Correlation coefficient between urinary chromium levels and both sister chromatid exchanges and tumor marker (CA15-3) levels in steel workers.

\begin{tabular}{|c|c|c|}
\hline \multirow{2}{*}{} & \multicolumn{2}{|c|}{ Urinary $\mathrm{Cr}(\mu \mathrm{g} / \mathrm{L})$} \\
\cline { 2 - 3 } & $\mathrm{r}$ & $\mathrm{P}$-value \\
\hline $\mathrm{SCE} /$ cell & 0.5 & $<0.05$ \\
\hline $\mathrm{CA} 15-3(\mathrm{U} / \mathrm{ml})$ & 0.98 & $<0.001$ \\
\hline
\end{tabular}

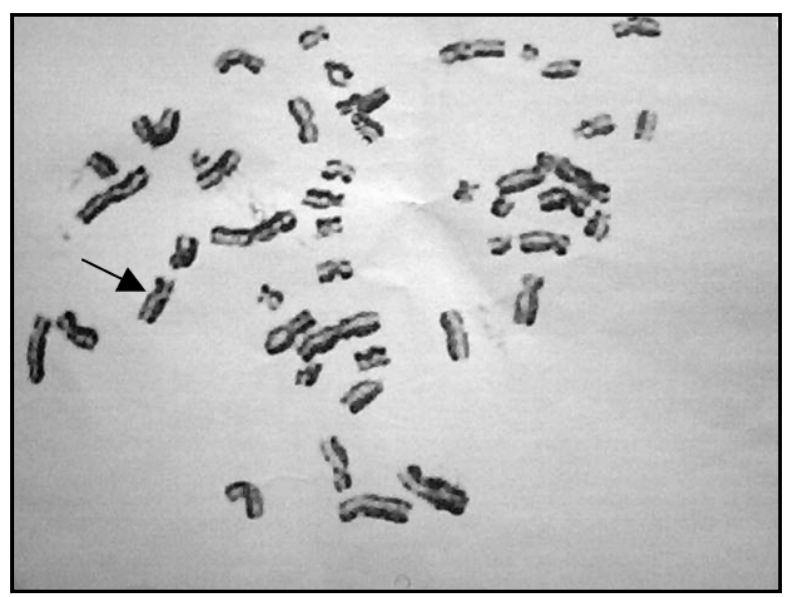

Figure (1): Sister chromatid exchanges frequencies in a normal non-exposed worker (a negative control). 


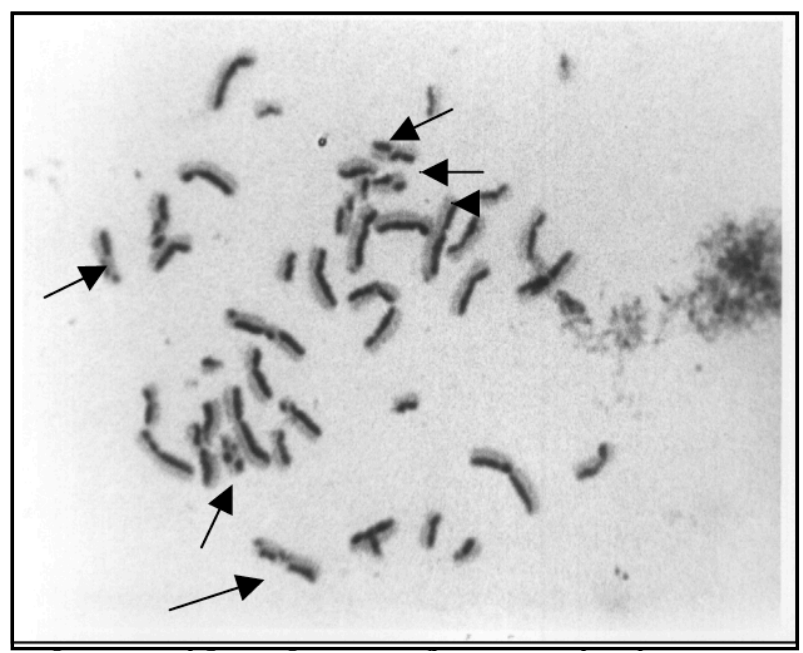

Figure (2): Sister chromatid exchanges frequencies in an exposed worker.

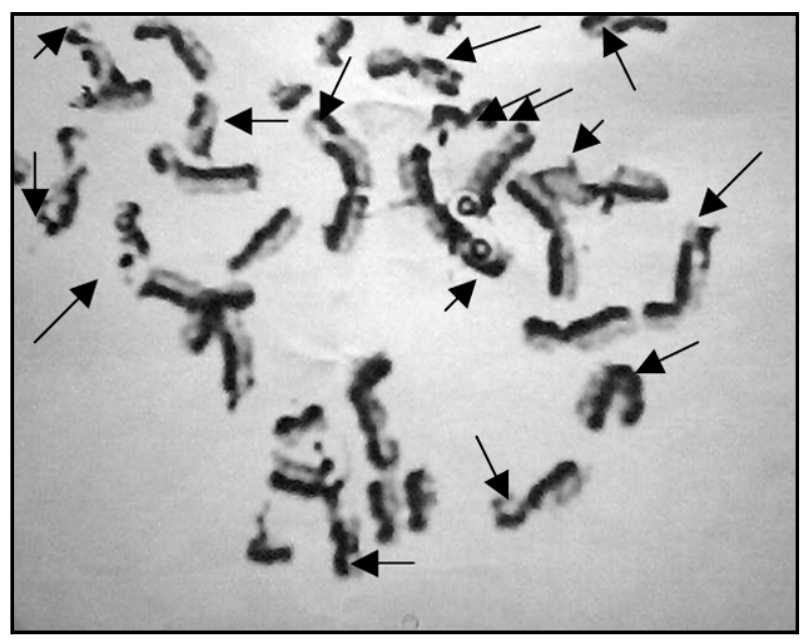

Figure (3): Sister chromatid exchanges frequencies in a lung cancer case (a positive control). 


\section{Discussion}

Several million workers worldwide are exposed to airborne fumes, mists, and dust containing chromium or its compounds (Schaller, 1996). Highest exposures to hexavalent chromium (VI) may occur during industrial chrome plating, welding, painting, metal finishes, steel and alloys manufacturing, and wood treatment. Hexavalent chromium $\left(\mathrm{Cr}^{+6}\right)$ is a proven human and animal toxin, mutagen, and carcinogen (Flora, 2000 and Bagchi et al., 2002).

The determination of the concentration of chromium in urine seems to be the most practical for biological monitoring purposes in workers occupationally exposed to chromium compounds (Schaller, 1996). In the present study, the results revealed that, the mean of the urinary chromium levels in the studied steel workers $(5.5 \pm 1.01 \mu \mathrm{g} /$ L) was significantly higher compared to the other two groups $(0.7 \pm 0.19 \mu \mathrm{g} / \mathrm{L}$, in negative controls and $0.8 \pm 0.22 \mu \mathrm{g} / \mathrm{L}$, in positive controls $)(\mathrm{P}<0.001)$. This is in agreement with the results of other studies; in which urinary chromium levels of steel production and chromium electroplating workers were significantly higher than those of the controls (Hornq \& Lin, 1996 and Lai et al., 1998). Also, in this study, urinary chromium levels of steel workers were much higher compared to the current reference values for median urinary chromium levels of the general population $(0.4$ $\mu \mathrm{g} / \mathrm{L}$ ) (with a range of 0.24 to $1.8 \mu \mathrm{g} / \mathrm{L}$ ) (Franchini et al., 1984).

Mutagens have the capacity to produce genotoxic problems, primarily cancer and congenital abnormalities. Cytogenetic analysis of chromosomal aberrations, detection of sister chromatid exchanges (SCEs), micronucleus assays, and macromolecular adducts detection have been developed in an attempt to monitor human populations for exposure to environmental mutagens (Baxter, 2007). SCE analysis is considered as one of the few direct methods that can measure mutation or other forms of DNA-induced damage in humans exposed to potential mutagens or carcinogens. This depends on measuring the gross changes occurring in the DNA that can be visualized by looking at the chromosomes through a light microscope (Hamamy et al., 1992). Also, it was reported that SCE has served as a test for the mutagenic and carcinogenic potential of many chemical and physical agents both in vivo and in vitro (Edelman and Lin, 2001). SCEs have been defined as the interchange of DNAreplication products at apparently homologous chromosomal loci (Latt and Sckreck, 1980). 
Taking all these facts into consideration, in this study SCEs were evaluated in the three studied groups. The present results revealed that, SCEs in steel workers were significantly higher compared to those in the negative controls (nonexposed workers $)(\mathrm{P}<0.001)$. This agrees with another study, where SCEs / cell values were significantly higher in chromium electroplating workers compared to their controls (10.6 versus 8.3 SCEs/cell). So, the authors concluded that, SCE in lymphocytes is useful for evaluating the biological effects of environmental mutagens (Lai et al., 1998). Alternatively, other studies didn't find significant effect of occupational chromium exposure on SCE frequency in stainless steel welders (Littorin et al., 1983) and in chromium plating workers (Nagayat et al., 2001); where it was suggested that SCE analysis in human lymphocytes is not a good indicator of possible mutagenic effects of exposure to hexavalent chromium. This contradiction may be attributed to different exposure levels of chromium.

Tumor markers are measurable biomarkers that are associated with malignancy. They are either produced by tumor cells (tumor-derived) or by the body in response to tumor cells (tumor-associated). They are typically substances that are re- leased into the circulation and so may be useful for screening or early detection of tumors. Some tumor markers are always elevated in specific cancers. Tumor markers are mostly found in low levels in healthy persons or can be associated with non-neoplastic diseases, as well as cancer (Nordenson, 2006). CA 15-3 is elevated mainly in breast cancer. CA 15-3 also may be elevated in individuals with other cancers or diseases; such as colorectal cancer, lung cancer, cirrhosis, hepatitis, and benign breast diseases (American Association for Clinical Chemistry, 2006). In the present study, the tumor marker levels (CA15-3) were evaluated in the three studied groups. The results of this study demonstrated that the mean of the tumor marker (CA15-3) levels in steel workers (28.8 \pm $5.03 \mathrm{U} / \mathrm{ml}$ ) was significantly higher compared to the negative controls (nonexposed workers) $(4.2 \pm 1.1 \mathrm{U} / \mathrm{ml})$ $(\mathrm{P}<0.001)$. The results of the present study were confirmed by other studies; where inhaled particulate forms of hexavalent chromium was found to be associated with increased lung cancer risk (Feng et al., 2003 and Xie et al., 2004). Also, from the epidemiological studies, there is suggestive evidence that hexavalent $\mathrm{Cr}$ causes increased risk of bone, prostate, lymphomas, leukemia, stomach, genital, renal, and 
bladder cancer; reflecting the ability of hexavalent chromate to penetrate all tissues in the body (Costa, 1997). It was revealed that, hexavalent chromium can cross cell membranes but it has a short intracellular life, reducing "within minutes to hours" to the potentially carcinogenic trivalent state. The reduction of $\mathrm{Cr}$ (VI) in the cell is associated with the generation of reactive oxygen species and radicals, and also lower valence forms which form stable complexes with intracellular macromolecules which can account for the DNA damage (Goulart et al., 2005).

Despite all previous findings it was found that, SCEs and tumor marker (CA15-3) levels were still significantly lower in steel workers compared to the positive controls (lung cancer patients) $(\mathrm{P}<0.01)$. This means that steel workers are in a stage, in which removal from further exposure to chromium is mandatory before carcinogenicity become well established.

In the present study there were significant positive correlations between urinary chromium levels and SCEs frequencies and tumor marker (CA15-3) levels in the studied steel workers. This is in agreement with other study conducted on electroplating workers; in which the frequency of SCE was significantly correlated with uri- nary chromium concentrations and duration of exposure (Wu et al., 2001).

\section{Conclusion}

So, it could be concluded that, occupational exposure to chromium in steel production industry can carry the risk of developing cytogenetic changes and cancer. These effects can be predicted by estimation of sister chromatid exchange frequencies and tumor marker (CA 15-3) levels.

\section{Recommendations}

Applying a suitable program for controlling chromium genotoxicity in chromium-alloyed steel foundries is mandatory, which should include the following:

1-Continuous engineering improvements, which involve enclosure of the re-melt process for minimizing the resulting emissions and providing the foundries with efficient local exhaust ventilation system.

2-Protective measures should be used to prevent excessive exposure to chromium aerosols in steel industries.

3-Continous safety education of workers about the importance of proper and regular use of the protective equipment.

4-Pre-employment medical examination to exclude susceptible workers. 
5-Periodic environmental as well as biological monitoring; using urinary chromium, sister chromatid exchange frequency, and tumor marker CA 15-3.

6-Removal from further exposure should be mandatory for workers with increased urinary chromium levels, sister chromatid exchanges frequencies, and tumor marker CA 15-3 levels.

7-Restriction of smoking is important to minimize its synergistic effect.

\section{Acknowledgement}

We wish to thank all workers for their cooperation and the mangers of the factories for making this study possible.

\section{References}

1. American Association for Clinical Chemistry (2006): CA 15-3. Available at website: www.labtestsonline.org/understanding/analytes/ ca15-3/test.html.

2. Bagchi D., Stohs S.J., Downs B.W. et al., (2002): Cytotoxicity and oxidative mechanisms of different forms of chromium. Toxicology; 180 (1):5-22.

3. Baxter C.S. (2007): Environmental Mutagenesis. In: Rom W.N and Markowitz S.B.. (eds.): Environmental and Occupational Medicine, 4th edition. Lippincott Williams \& Wilkins Publishers. Chap. (11); pp: 131-142.

4. Costa M. (1997): Toxicity and carcinogenicity of $\mathrm{Cr}$ (VI) in animal models and humans. Crit. Rev. Toxicol; 27 (5): 431-442.
5. Edelman J.R. and Lin Y.J. (2001): SCE mechanism. Translocation of heterochromatin. Cytobios; 106:171-191.

6. Feng Z., Hu W., Rom W.N. et al., (2003): Chromium (VI) exposure enhances polycyclic aromatic hydrocarbon-DNA binding at the p53 gene in human lung cell. Carcinogenesis; 24 (4): 771-778.

7. Flora D.S. (2000): Threshold mechanisms and site specificity in chromium (VI) carcinogenesis. Carcinogenesis; 21(4):533-541.

8. Franchini R., Mutti A., Cavatorta E. et al., (1984): Chromium. In: Biological indicators for the assessment of human exposure to industrial chemicals. Alessio L. et al., (eds.).Commission of the European Communities.

9. Goulart M., Batoreu M.C., Rodrigues A.S. et al., (2005): Lipoperoxidation products and thiol antioxidants in chromium exposed workers. Mutagenesis; 20 (5): 311-315.

10. Hamamy H., Shubber E.K. and Al-Allak B.M.A. (1992): Sister chromatid exchange frequencies in a group of individuals with unfavorable reproductive health. Europ. J. Obstet. Reprod. Biol; 43: 45-49.

11. Hornq C.J. and Lin S.R. (1996): Determination of urinary zinc, chromium, and copper in steel production workers. Biol. Trace Elem. Res; 55 (3): 307-314.

12. Huvinen M., Uitti J., Zitting A. et al., (1996): Respiratory health of workers exposed to low levels of chromium in stainless steel production. Occup. Environ. Med; 53:741-747. 
13. Lai J.S., Kuo H.W., Liao F.C. and Lien C.H. (1998): Sister chromatid exchange induced by chromium compounds in human lymphocytes. Inter. Arch. Occup. Environ. Health; 71: 550553.

14. Latt SA and Sckreck RR (1980). Sister chromatid exchange analysis. Am. J. Hum. Genet; 32: 297-313.

15. Littorin M., Hogstedt B., Stromback B. et al., (1983): No cytogentic effects in lymphocytes of stainless steel welders. Scand. J. Work Environ. Health; 9 (3): 259-264.

16. Nagayat T., Ishikawa N. and Hata H. (2001): Sister chromatid exchange analysis in lymphocytes of workers exposed to hexavalent chromium. Br. J. Ind. Med; 46 (1): 48-51.

17. Neter J., Wasserman W. and Whitmore G.A. (1993): Applied statistics. A Division of Simon \& Schuster, Inc., USA.

18. Nordenson N.J. (2006): Tumor markers. Available at website: www.healthatoz.com.

19. Sawyer H.J. (1994): Chromium and its compounds. In Zenz C., Dickerson B.O. and Horvath E.P. (eds.): Occupational Medicine. 3rd ed. Mosby Publisher. Chap.(39); pp: 542-548.

20. Schaller K.H. (1996): Selected metals. In: WHO, Biological monitoring of chemical expo- sure in the work place guidelines. Vol.(1). Chap. (3); pp: 91-107.

21. Stearns D.M. and Wetterhahn K.E. (1994): Reaction of $\mathrm{Cr}(\mathrm{VI})$ with ascorbate produces $\mathrm{Cr}$ (V), $\mathrm{Cr}(\mathrm{IV})$ and carbon based radicals. Chem. Res. Toxicol; 7:219-230.

22. -Trzeciak A., kowalik J., Panas et al., (2000): Genotoxicity of chromium (VI) in peripheral blood lymphocytes. Med. Sci. Monit; 6(1):2429.

23. Verma R.S. and Babu A. (1989): Human Chromosomes. Manual of Basic Techniques. New York, Academic Press.

24. Wu F.Y., Wu W.Y., Kuo H.W. et al., (2001): Effect of genotoxic exposure to chromium among electroplating workers in Taiwan. Sci. Total Environ; 279 (1-3): 21-28.

25. Xie H., Holmes A.L., Wise S.S. et al., (2004): Lead chromate-induced chromosome damage requires extracellular dissolution to liberate chromium ions but doesn't require particle internalization or intracellular dissolution. Chem. Res. Toxicol; 17 (10): 1362-1367.

26. Zhitjovich A., Quievryn G., Messer J. and Motylevich (2002): Induction of genotoxicity by carcinogenic chromium (VI). Environ. Health Persp; 110: 172-181. 